CZASOPISMO INŻYNIERII LĄDOWEJ, ŚRODOWISKA I ARCHITEKTURY JOURNAL OF CIVIL ENGINEERING, ENVIRONMENT AND ARCHITECTURE

JCEEA, t. XXXIV, z. 64 (3/I/17), lipiec-wrzesień 2017, s. 341-350, DOI: 10.7862/rb.2017.127

\author{
Rafał KRZYWON' ${ }^{1}$ \\ Jacek HULIMKA ${ }^{2}$ \\ Agnieszka JĘDRZEJEWSKA ${ }^{3}$
}

\title{
TECHNICZNE MOŻLIWOŚCI ZBROJENIA PIANOBETONOWYCH PLYT FUNDAMENTOWYCH
}

\begin{abstract}
Właściwości fizyczne pianobetonu sprawiają, że świetnie sprawdza się on jako grubowarstwowy podkład pod fundamenty płytowe. Teoretycznie mógłby pełnić również rolę warstwy konstrukcyjnej, jednak, głównie z uwagi na duży skurcz powodujący niebezpieczeństwo niekontrolowanego samodylatowania się płyty, niezbędne jest stosowanie kilkucentymetrowej grubości płyty wierzchniej z betonu zwykłego zbrojonego siatką z prętów stalowych. Alternatywnym rozwiązaniem jest wprowadzenie zbrojenia, najlepiej odpornego na korozję, w strukturę pianobetonu. Artykuł przedstawia badania pilotażowe płyt pianobetonowych o gęstości $800 \mathrm{~kg} / \mathrm{m}^{3}$, zbrojonych rusztami kompozytowymi z włóknem węglowym CFRP i bazaltowym BFRP. Dzięki wprowadzeniu takiego zbrojenia uzyskano kilkukrotny wzrost nośności na zginanie oraz znaczny wzrost sztywności. Badania wykazały również, że nawet całkowite pęknięcie próbki spowodowane skurczem nie ogranicza jej nośności, a poprzeczne żebra siatki zapewniają wystarczającą jej przyczepność.
\end{abstract}

Słowa kluczowe: pianobeton, siatka CFRP, siatka BFRP, fundament płytowy, zbrojenie

\section{Wstęp}

Pianobeton znajduje zastosowanie w budownictwie głównie jako materiał wypełniający i wyrównujący. Po dodaniu piany technicznej, beton nawet kilkukrotnie zwiększa swoją objętość, dzięki czemu jego koszt jest znacznie niższy niż tzw. chudych betonów. Równocześnie poprawia się rozpływalność, co sprawia, że materiał świetnie nadaje się do wypełniania wykopów czy kanałów. Wy-

\footnotetext{
1 Autor do korespondencji / corresponding author: Rafał Krzywoń, Politechnika Śląska, Katedra Inżynierii Budowlanej, ul. Akademicka 5, 44-100 Gliwice; tel. 322372262; rafal.krzywon@polsl.pl

2 Jacek Hulimka, Politechnika Śląska, Katedra Inżynierii Budowlanej, ul. Akademicka 5, 44-100 Gliwice; tel. 322371126; jacek.hulimka@polsl.pl

3 Agnieszka Jędrzejewska, Politechnika Śląska, Katedra Inżynierii Budowlanej, ul. Akademicka 5, 44-100 Gliwice; tel. 322371598; agnieszka.jedrzejewska@ polsl.pl
} 
trzymałość około $1 \div 2 \mathrm{MPa}$ pozwala na zastępowanie pianobetonem tradycyjnej podbudowy dróg i posadzek [1], przy czym odpada kosztowny proces ich zagęszczania. Drugą szczególną cechą pianobetonu jest dobra izolacyjność termiczna i akustyczna. Dzięki temu świetnie sprawdza się jako substytut styropianu lub szkła piankowego w warstwach podłóg pływających [2]. Rzadsze, choć znane autorom artykułu, są zastosowania pianobetonu w konstrukcji ścian, a nawet stropów budynków, głównie w budownictwie jednorodzinnym [3-5].

Obydwie z wymienionych zalet pianobetonu sprawiły, że autorzy niniejszego artykułu kilka lat temu współtworzyli nowatorską koncepcję „,ciepłego” fundamentu płytowego dla budynków pasywnych [6]. Ideą koncepcji jest ,sandwichowa" konstrukcja płyty fundamentowej, w której rolę warstwy podkładowej i izolacyjnej pełni pianobeton. Przykład tego rozwiązania pokazano na rys. 1. Niestety, z uwagi na duże odkształcenia skurczowe pianobeton znacznie silniej niż beton zwykły ulega zarysowaniu w trakcie dojrzewania. Rysy skurczowe mogą prowadzić do niekontrolowanego samodylatowania się płyty pianobetonowej. Z tej przyczyny konieczne było wprowadzenie do konstrukcji fundamentu zbrojonej płyty żelbetowej, dodatkowo pogrubionej pod ścianami nośnymi. Takie rozwiązanie sprawdziło się na budowie kilkunastu budynków w Polsce i na Słowacji, które do dnia dzisiejszego są z powodzeniem eksploatowane. $\mathrm{Na}$ rysunku 2. pokazano etapy wykonywania takiej płyty.

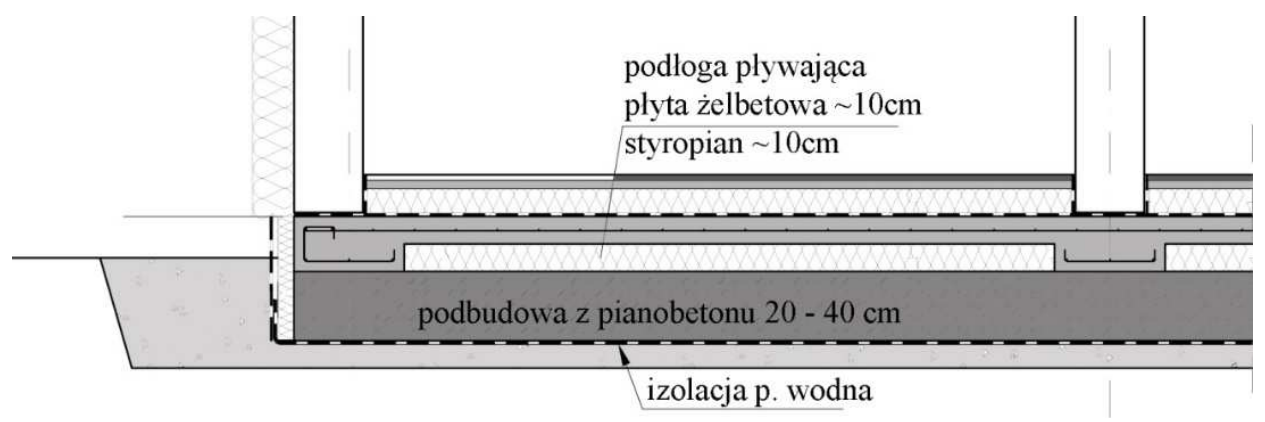

Rys. 1. Konstrukcja fundamentowej płyty pianobetonowej

Fig. 1. Structure of foam concrete foundation slab

Dodatkowa, wierzchnia płyta żelbetowa mocno komplikuje zadanie budowlane, a jej wykonanie jest kosztowne i pracochłonne. Niedogodność ta skłoniła autorów do poszukiwania rozwiązania pozwalającego wyeliminować konieczność jej zastosowania. Oczywistą modyfikacją było wprowadzenie zbrojenia w konstrukcję płyty pianobetonowej. Niestety, z uwagi na miejsce zastosowania, nie mogło to być zbrojenie stalowe, które łatwo ulega korozji. Dodatkowo, miękki pianobeton nie zapewnia wystarczającej przyczepności do prętów zbrojenia, toteż niezbędne jest wprowadzenie dodatkowych kotwiących elementów oporowych, np. w formie prętów prostopadłych. Rozwiązanie znaleziono podpa- 
trując techniki wzmacniania podłoży za pomocą dwukierunkowych georusztów. Dzięki sztywnym węzłom wzajemnie prostopadłe żebra rusztu mogą zapewnić wymaganą współpracę $\mathrm{z}$ pianobetonem, a oczko o przekroju przynajmniej $20 \mathrm{~mm}$ umożliwia poprawne ułożenie i rozpływ pianobetonu w deskowaniu. Niestety, typowe georuszty polipropylenowe mają relatywnie niski moduł sprężystości, w związku z czym mogą nie zapewniać wystarczającej ochrony przed rozwojem rys skurczowych. Alternatywą mogą być ruszty zbrojone włóknami wysokiej wytrzymałości, droższe, ale znacznie wytrzymalsze i sztywniejsze. Tego typu materiały ostatnio pojawiły się na rynku z przeznaczeniem do wzmacniania podłoży, ale również do zbrojenia cienkich powłok betonowych, tynków i murów.
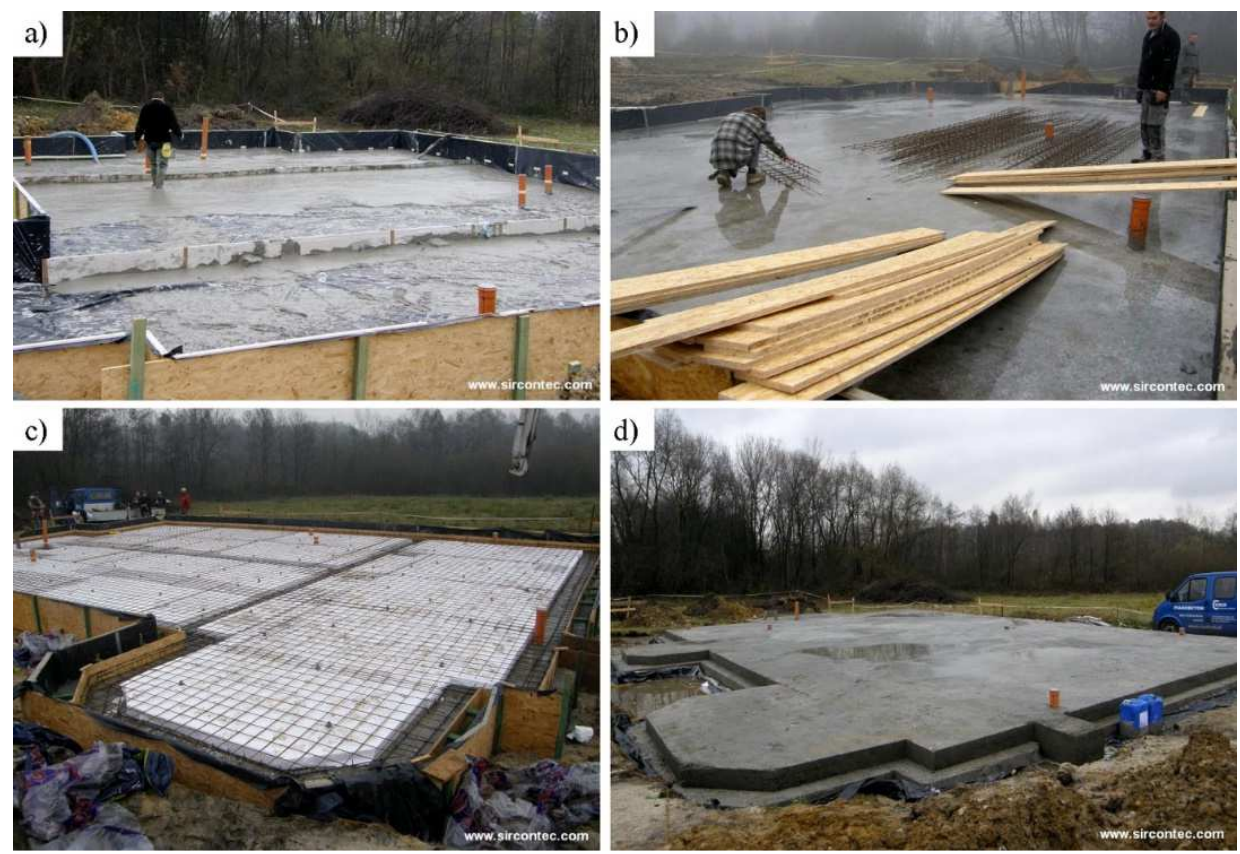

Rys. 2. Etapy wykonywania pianobetonowej płyty fundamentowej: a) układanie pianobetonu; b) wyrównywanie powierzchni; c) dodatkowe docieplenie i zbrojenie wierzchniej płyty żelbetowej; d) gotowy fundament [7]

Fig. 2. Stages of foam concrete foundation slab execution: a) casting of foam concrete; b) surface levelling; c) additional insulation and reinforcement of top reinforced concrete slab; d) ready foundation [7]

Przedstawione w artykule badania dotyczą zginania modeli płyt pianobetonowych zbrojonych dwoma typami wysokowytrzymałych siatek kompozytowych (FRP - Fiber Reinforced Polymer). Analizowano wpływ zbrojenia na nośność i odkształcalność próbek zbrojonych w strefie rozciąganej. 


\section{Właściwości pianobetonu}

Pianobeton jest szczególnym typem betonu komórkowego, w którym porowata struktura jest uzyskiwana po dodaniu piany technicznej. Jego właściwości zależą w głównej mierze od gęstości, która dla najlżejszych pianobetonów może wynosić około $300 \mathrm{~kg} / \mathrm{m}^{3}$. Szczegółowy opis cech pianobetonu można znaleźć w pracach [4, 8-10].

Właściwości wytrzymałościowe pianobetonu są głównie pochodną jego gęstości. Podobnie jak w przypadku betonów zwykłych, można je poprawić stosując dodatki włókien polipropylenowych [9] lub winylowych [11]. Z uwagi na dużą porowatość ułatwiona jest migracja wody w strukturze pianobetonu, przez co jest on podatny na przedwczesne wysychanie w trakcie wiązania, to zaś skutkuje niebezpieczeństwem wystąpienia znacznych odkształceń skurczowych. Można temu częściowo przeciwdziałać stosując wypełniacze, np. w formie kulek styropianowych.

Pomimo znacznej porowatości pianobeton cechuje zadowalająca mrozoodporność. Zachowuje on również dobrą odporność ogniową. Z uwagi na wysoką sorpcyjność nie stanowi wystarczającej ochrony dla stali zbrojeniowej, co ogranicza możliwość zastosowania typowego zbrojenia, zwłaszcza w środowiskach agresywnych.

\section{Opis procedury badawczej}

Badania objęły 23 modele płyt, w tym 5 referencyjnych, nie zawierających zbrojenia i po 9 modeli ze zbrojeniem w formie sztywnej siatki (rusztu) zbrojonej włóknem bazaltowym (BFRP) i sztywnej siatki z włóknem węglowym (CFRP). Badaniom zasadniczym towarzyszyły badania właściwości materiałowych.

Wszystkie badane modele zostały wykonane z jednego zarobu. Projektowana gęstość pianobetonu wynosiła $800 \mathrm{~kg} / \mathrm{m}^{3}$ i była dodatkowo kontrolowana dla każdej z próbek podczas badań. Mieszanka pianobetonowa została wykonana z cementu portlandzkiego, niewielkiej ilości żwiru, wody, piany technicznej, dodatku mikrowłókien polipropylenowych i superplastyfikatora. Próbki dojrzewały w pomieszczeniu, w temperaturze około $+10^{\circ} \mathrm{C}$. W pierwszej fazie wiązania modele okryto płytami styropianowymi w celu poprawy cieplnowilgotnościowych warunków dojrzewania betonu. Główne parametry pianobetonu określono w badaniach próbek kostkowych i walcowych, które przeprowadzono równocześnie z badaniami zasadniczymi pierwszych płyt zginanych, tj. w wieku 54 dni od zabetonowania. Zgodnie z wymaganiami normy PN-EN 12390-3:2009 [12], wytrzymałość na ściskanie $\mathrm{f}_{\mathrm{c}, \text { cube }}$ określono $\mathrm{w}$ badaniu sześciu kostek o wymiarach boku $120 \mathrm{~mm}$ (wyciętych z płyty); wytrzymałość słupową $\mathrm{f}_{\mathrm{c}}$ oraz sieczny moduł sprężystości $\mathrm{E}_{\mathrm{c}}$ oznaczono $\mathrm{w}$ badaniu sześciu walców $150 \times 300 \mathrm{~mm}$. Uśrednione wyniki tych badań pokazano w tabeli 1 . 


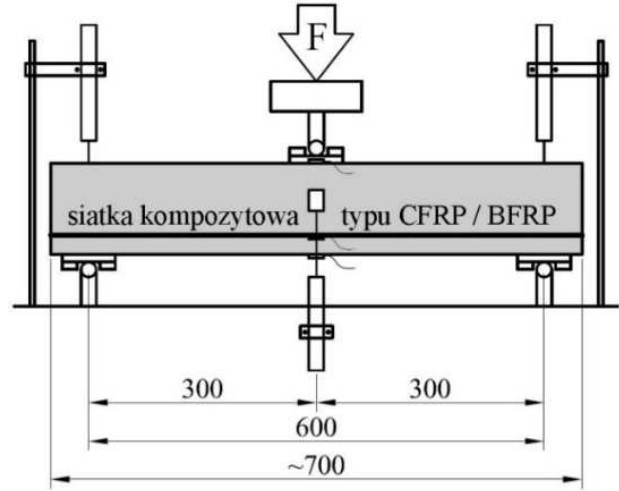

\$ czujnik przemieszczeń

个 tensometr elektrooporowy

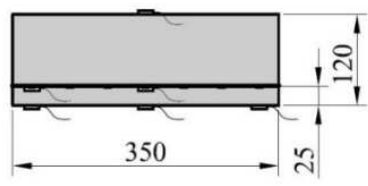

Rys. 3. Schemat badania płyty

Fig. 3. Scheme of test set-up

Tabela 1. Określone w badaniach właściwości dojrzałego pianobetonu

Table 1. Properties of hardened foam concrete determined in laboratory tests

\begin{tabular}{|c|c|c|c|}
\hline $\begin{array}{c}\text { Wiek pianobetonu } \\
{[\mathbf{d n i}]}\end{array}$ & $\begin{array}{c}\mathbf{f}_{\mathbf{c}} \\
{[\mathbf{M P a}]}\end{array}$ & $\begin{array}{c}\mathbf{f}_{\mathbf{c}, \text { cube }} \\
{[\mathbf{M P a}]}\end{array}$ & $\begin{array}{c}\mathbf{E}_{\mathbf{c}} \\
{[\mathbf{G P a}]}\end{array}$ \\
\hline 54 & 1,68 & 1,87 & 1,65 \\
\hline
\end{tabular}

Siatki do zbrojenia modeli badawczych dobrano tak, aby zbliżona była siła zrywająca, z uwagi na zastosowany rodzaj włókien. Różni je natomiast geometria oraz wynikająca z typu zastosowanych włókien odkształcalność. Szczególne właściwości zastosowanych siatek zebrano w tabeli 2.

Tabela 2. Właściwości kompozytowych siatek zbrojeniowych

Table 2. Properties of composite reinforcing grids

\begin{tabular}{|l|l|l|}
\hline & \multicolumn{1}{|c|}{ BSC220.220.260.100 [13] } & C-GRID®C50-2.36×2.36 [14] \\
\hline Rodzaj włókien & Ciągłe włókno bazaltowe & Włókno węglowe \\
\hline Rozmiar oczka siatki & $25 \mathrm{~mm} \times 25 \mathrm{~mm}$ & $60 \mathrm{~mm} \times 60 \mathrm{~mm}$ \\
\hline Szerokość rolki & $1,0 \mathrm{~m}$ & $1,2 \mathrm{~m}$ \\
\hline Siła zrywająca & $>50 \mathrm{kN} / \mathrm{m}$ & $>54,17 \mathrm{kN} / \mathrm{m}$ \\
\hline Wydłużenie przy zerwaniu & $2,5 \pm 1 \%$ & $0,99 \%$ \\
\hline $\begin{array}{l}\text { Moduł sprężystości przy } \\
\text { rozciąganiu }\end{array}$ & $86 \div 94 \mathrm{GPa}$ & $234,5 \mathrm{GPa}$ \\
\hline Inne właściwości & $\begin{array}{l}\text { Odporność korozyjna, niewielki } \\
\text { ciężar, bardzo dobra przyczep- } \\
\text { ność do betonu }\end{array}$ & $\begin{array}{l}\text { Odporne w środowisku che- } \\
\text { micznie agresywnym, łatwe } \\
\text { waplikacji, obojętne elektrycznie }\end{array}$ \\
\hline Zalecane miejsca aplikacji & $\begin{array}{l}\text { Płyty na sztywnym podłożu, } \\
\text { tynki, betony osłonowe, ściany } \\
\text { silosów i zbiorników, betony } \\
\text { natryskowe, prefabrykaty małej } \\
\text { architektury }\end{array}$ & $\begin{array}{l}\text { Przemysł budowlany, zbrojenie } \\
\text { zapraw, tynków, betony nie } \\
\text { spełniające funkcji konstrukcyj- } \\
\text { nej }\end{array}$ \\
\hline
\end{tabular}


Badane modele płyty miały przekrój nominalny $120 \times 350 \mathrm{~mm}$. Siatkę umieszczono w odległości około $25 \mathrm{~mm}$ od dolnej powierzchni. $\mathrm{Z}$ uwagi na podatność siatki, uległa ona $\mathrm{w}$ trakcie betonowania niewielkim przemieszczeniom na wysokości przekroju, dlatego przed badaniem dokonywano kontrolnego pomiaru położenia siatki w elemencie. Płyty badano w teście trójpunktowego zginania, którego schemat pokazano na rysunku 3. Prędkość przyrostu obciążenia w trakcie całego testu była stała i wynosiła $0,05 \mathrm{kN} / \mathrm{s}$. W trakcie badania mierzono ugięcia za pomocą przetworników przemieszczeń typu LVDT oraz odkształcenia górnej i dolnej powierzchni płyty w strefie środkowej za pomocą naklejanych tensometrów elektrooporowych o bazie $10 \mathrm{~mm}$. Dodatkowo, bok próbki oznaczono siatką markerów umożliwiającą optyczną analizę odkształceń powierzchniowych; samo badanie utrwalono serią zdjęć poklatkowych o interwale $2 \mathrm{~s}$.

\section{Wyniki badań modeli zginanych}

Podstawowym wskaźnikiem efektywności zastosowanego zbrojenia jest wartość siły niszczącej próbkę. Rezultaty badań w tym zakresie należy uznać za bardzo obiecujące. Zestawiono je w tabeli 3. Zgodnie z oczekiwaniami, największą nośność zanotowano dla próbek zbrojonych siatką z włókien węglowych. Najwyższa siła niszcząca wyniosła w tym przypadku $11,79 \mathrm{kN}$, natomiast średnia 9,20 kN. Skuteczność siatki bazaltowej okazała się nieco niższa - średnia siła niszcząca sięgnęła $8,74 \mathrm{kN}$. Co istotne, w obydwu przypadkach wzrost nośności w porównaniu do modeli bez zbrojenia jest ponad sześciokrotny.

Na rysunku 4. pokazano typowy przebieg badania elementu zbrojonego. $\mathrm{W}$ żadnym z testów nie doszło do zniszczenia w wyniku zerwania włókien siatki kompozytowej. W pierwszej fazie dochodziło do rozwarcia rys prostopadłych w strefie maksymalnego momentu zginającego. W modelach bez zbrojenia wystąpienie tych rys było równoznaczne z osiągnięciem nośności, natomiast w modelach zbrojonych rozciąganie $\mathrm{w}$ przekroju rysy przejmowały włókna siatki. Towarzyszyło temu powstawanie kolejnych rys prostopadłych, stopniowo przechodzących w ukośne w miarę zbliżania się do podpory. Ostatecznie, do zniszczenia dochodziło $\mathrm{w}$ wyniku rozwoju rysy ukośnej i poziomego ścięcia próbki przebiegającego w płaszczyźnie zbrojenia. Można zatem uznać, że poprzeczne włókna siatki spełniły swoją rolę jako zakotwienie dla włókien podłużnych, równocześnie jednak przyczyniły się do ścięcia poziomego w płaszczyźnie siatki.

Przyczyną wcześniejszego zniszczenia próbek zbrojonych siatką bazaltową był niższy moduł sprężystości włókien siatki. Tym samym, wskutek przyrostu krzywizny modelu, następował szybszy rozwój rys oraz szybszy przyrost naprężeń stycznych powodujących opisany wcześniej model zniszczenia. Pomimo niewielkiego stopnia zbrojenia, wynoszącego około $0,05 \%$, wpływ zastosowanych siatek na sztywność zginania jest bardzo duży. Około 2,5-krotne większy moduł sprężystości siatki węglowej w porównaniu do siatki bazaltowej pozwala zredukować ugięcia nawet do $40 \%$. Jest to spowodowane bardzo niskim modu- 
łem sprężystości samego pianobetonu. Określone w badaniach $\mathrm{E}_{\mathrm{c}}=1,65 \mathrm{GPa}$ jest wartością prawie dwudziestokrotnie niższą niż w typowym betonie zwykłym i ponad stukrotnie niższą niż moduł sprężystości włókien siatki węglowej.

Tabela 3. Wybrane wyniki badań płyt pianobetonowych

Table 3. Chosen results of foam concrete slabs tests

\begin{tabular}{|c|c|c|c|c|}
\hline Model & Rodzaj zbrojenia & $\begin{array}{c}\text { Gęstość piano- } \\
\text { betonu } \\
{\left[\mathrm{kg} / \mathrm{m}^{3}\right]}\end{array}$ & $\begin{array}{c}\text { Siła niszcząca } \\
{[\mathrm{kN}]}\end{array}$ & $\begin{array}{l}\text { Ugięcie w chwili } \\
\text { zniszczenia } \\
\text { [mm] }\end{array}$ \\
\hline $\mathrm{FC}_{-} 1$ & \multirow{6}{*}{ brak } & 778 & 0,95 & 0,98 \\
\hline FC_2 & & 793 & 1,20 & 1.13 \\
\hline FC_3 & & 778 & 1,27 & 1,39 \\
\hline FC_4 & & 752 & 1,68 & 0,58 \\
\hline FC_5 & & 752 & 1,46 & 0,41 \\
\hline średnia & & 771 & 1,31 & 0,90 \\
\hline BC_1 & \multirow{10}{*}{ siatka bazaltowa } & 763 & 9,20 & 10,25 \\
\hline BC_2 & & 798 & 7,93 & 6,04 \\
\hline BC_3 & & 809 & 9,24 & 8,31 \\
\hline BC_4 & & 779 & 8,42 & 11,44 \\
\hline BC_5 & & 743 & 7,42 & 7,84 \\
\hline BC_6 & & 787 & 9,36 & 8,11 \\
\hline BC_7 & & 769 & 8,93 & 9,32 \\
\hline BC_8 & & 729 & 8,08 & 16,1 \\
\hline BC_9 & & 781 & 10,16 & 12,19 \\
\hline średnia & & 773 & 8,75 & 9,96 \\
\hline $\mathrm{CC}_{-} 1$ & \multirow{10}{*}{ siatka węglowa } & 767 & 11,79 & 7,46 \\
\hline CC_2 & & 774 & 10,75 & 7,91 \\
\hline CC_3 & & 744 & 9,96 & 6,57 \\
\hline $\mathrm{CC}_{-} 4$ & & 742 & 9,94 & 6,95 \\
\hline CC_5 5 & & 772 & 6,61 & 5,41 \\
\hline CC_6 & & 776 & 8,37 & 8,38 \\
\hline $\mathrm{CC}_{-} 7$ & & 768 & 9,77 & 3,81 \\
\hline CC_8 & & 724 & 7,99 & 11,26 \\
\hline CC_9 & & 731 & 7,58 & 6,19 \\
\hline średnia & & 755 & 9,20 & 7,10 \\
\hline
\end{tabular}

Jeden $\mathrm{z}$ badanych modeli (BC_7) uległ zarysowaniu skurczowemu na wskroś w strefie środkowej, czyli w strefie maksymalnego momentu zginającego. Zbrojenie pozostało jedynym elementem zespalających obie części modelu. Pomimo tego określona w badaniu nośność nie odbiega od nośności pozostałych tego typu próbek. Rezultat ten dowodzi, że wprawdzie zbrojenie nie zapobiega całkowicie powstawaniu rys skurczowych, jednakże wystarczająco skutecznie zszywa te rysy. Należy również podkreślić, że liczba rys skurczowych obserwowanych na próbkach zbrojonych była znacząco niższa niż na modelach referencyjnych, zbrojonych jedynie rozproszonym mikrowłóknem polipropylenowym. 

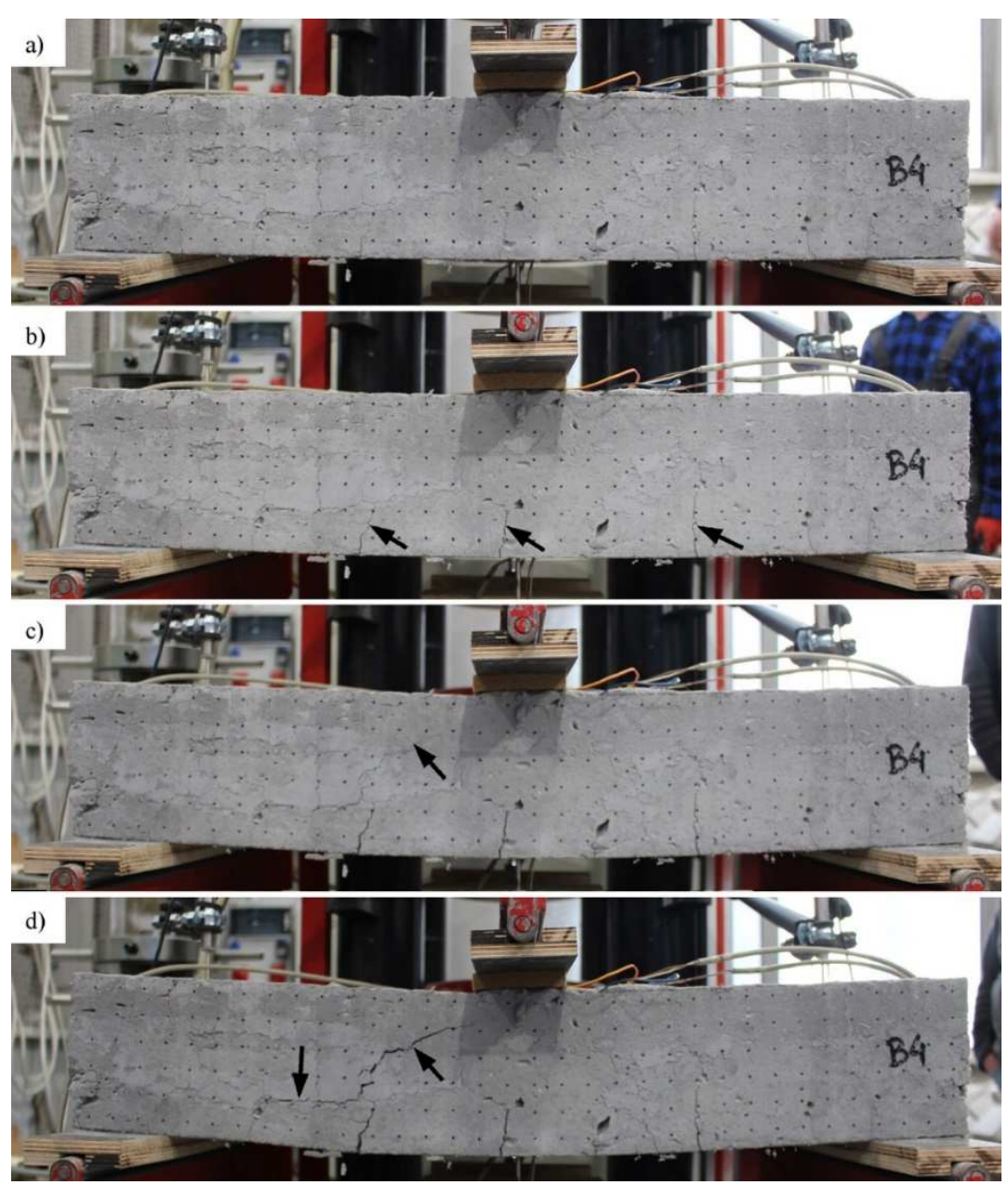

Rys. 4. Typowy przebieg badania modelu zbrojonego: a) początek badania - widoczne zarysowania skurczowe; b) rozwój rys prostopadłych; c) początek rozwoju rysy ukośnej; d) zniszczenie w wyniku ścięcia modelu w płaszczyźnie zbrojenia

Fig. 4. Typical process of reinforced model test: a) beginning of the test - visible shrinkage cracks; b) development of vertical cracks; c) initiation of slanting crack development; d) failure due to shear in the plane of reinforcing grid

\section{Podsumowanie}

Opisane badania niewątpliwie potwierdziły wysoki potencjał siatek kompozytowych do zbrojenia płyt pianobetonowych. Zarówno w przypadku nośności jak i sztywności zginania zanotowano znaczący, bo nawet kilkukrotny wzrost wyników w odniesieniu do referencyjnych modeli bez zbrojenia. 
Poprzeczne włókna siatki dobrze spełniają swoją rolę, zapewniając wystarczającą przyczepność, z drugiej jednak strony, z uwagi na stosunkowo niewielką grubość w przekroju, przyczyniają się one do zniszczenia mającego formę ścięcia próbki w płaszczyźnie siatki.

Zbrojenie kompozytowe skutecznie zszywa rysy prostopadłe, w tym skurczowe, dzięki czemu ewentualne, pierwotne zarysowanie nie wpływa znacząco na nośność płyty.

$\mathrm{W}$ żadnym $\mathrm{z}$ badanych modeli nie doszło do zniszczenia poprzedzonego zerwaniem włókien zbrojenia. Zauważalne znaczenie, z punktu widzenia nośności płyty, ma natomiast odkształcalność siatki kompozytowej. Dowodzi tego wyższa nośność modeli zbrojonych sztywniejszą siatka węglową. Należy jednakże podkreślić, że również siatka bazaltowa doskonale spełnia swoją rolę, zwłaszcza na tle wyników badań modeli referencyjnych.

Zastosowanie siatki węglowej do zbrojenia wielkopowierzchniowej płyty fundamentowej, z uwagi na wysoki koszt, jest obecnie ekonomicznie nieuzasadnione. Ponad trzykrotnie tańsza siatka bazaltowa stanowi już znacznie atrakcyjniejszą alternatywę. Innym rozwiązaniem może być zastosowanie tańszych siatek szklanych lub typowych georusztów polipropylenowych. Takie badania autorzy planują w najbliższej przyszłości, choć należy podkreślić, że w świetle już poznanych wyników, niewątpliwie istotną wadą najtańszych georusztów jest ich duża odkształcalność.

Przedstawione rezultaty badań dowodzą skuteczności zbrojenia pianobetonu, otwierając przed tym materiałem nowe obszary zastosowań, w tym również jako jednorodnych płyt fundamentowych. Rozwiązania w tym zakresie wymagają rozwiązania problemu technicznego związanego ze stabilizacją dość wiotkiego zbrojenia w trakcie układania mieszanki pianobetonowej w wykopie.

\section{Podziękowania}

Próbki do badań powstaty przy wspótpracy i dzięki pomocy technicznej firmy AKCES BK sp. z o.o. ${ }_{w}$ Czechowicach Dziedzicach.

\section{Literatura}

[1] Decký M., Drusa M., Zgútová K., Blaško M., Hájek M., Scherfel W.: Foam concrete as new material in road constructions. Procedia Engineering, 2016, s. 161, 428-433.

[2] Kadela M., Kozłowski M.: Foamed concrete layer as sub-structure of industrial concrete floor. Procedia Engineering, 161, 2016, s. 468-476.

[3] Singh G.B.: Site Produced Cellular Lightweight Concrete - a Boon for Housing. 2005, http://eco-web.com/edi/050113.html (dostęp 04.03.2017).

[4] Mugahed Amran Y.H., Farzadnia N., Abang Ali A.A.: Properties and applications of foamed concrete; a review. Constr. Build. Mater., 101, 2015, s. 990-1005.

[5] Othuman Mydin M.A., Wang Y.C.: Structural performance of lightweight steelfoamed concrete-steel composite walling system under compression, Thin Wall Struct., 49, 2011, s. 66-76. 
[6] Hulimka J., Krzywoń R., Knoppik-Wróbel A.: Use of foamed concrete in the structure of passive house foundation slab. Proc. 7th International Conference on Analytical Models and New Concepts in Concrete and Masonry Structures AMCM2011, Wyd. Pol. Krakowskiej, 2011, s. 221-222+CD.

[7] Płyty fundamentowe z PBG, http://www.sircontec.sk/page.php?id=826 (dostęp 04.03.2017).

[8] Narayanan N., Ramamurthy K.: Structure and properties of aerated concrete; a review. Cement Concrete Comp., 22, 2000, s. 321-329.

[9] Jones M. R., Mccarthy A.: Preliminary views on the potential of foamed concrete as a structural material. Magazine of Concrete Research, Vol. 57, No. 1, 2005, s. 21-31.

[10] Ramamurthy K., Kunhanandan Nambiar E.K., Indu Siva Ranjani G.: A classification of studies on properties of foam concrete. Cement Concrete Comp., 31, 2009, s. 388-396.

[11]Byun K.J., Song H.W., Park S.S., Song Y.C.: Development of structural lightweight foamed concrete using polymer foam agent. ICPIC-98 1998.

[12]PN EN 12390-3:2009 Testing hardened concrete. Compressive strength of test specimens.

\section{TECHNICAL POSSIBILITIES OF FOAM CONCRETE FOUNDATION SLABS REINFORCEMENT}

\section{S u m m a r y}

Due to its physical properties foam concrete is a perfect material for construction of thick base for slab foundations. Theoretically, it could be also used as a structural layer, however, mainly due to significant shrinkage and resulting risk of self-division of slab it is necessary to apply a few-centimetre thick top slab made of OPC reinforced with steel bars. Alternatively, reinforcement - preferably corrosion-resistant - can be introduced into the structure of foam concrete. The paper presents pilot tests of foam concrete slabs of $800 \mathrm{~kg} / \mathrm{m}^{3}$ density reinforced with composite grids made of carbon and basalt fibres. Thanks to application of such reinforcement flexural capacity of the slabs was increased almost 9 times in addition to an important increase in stiffness. The tests have also shown that even complete rupture of the specimen caused by shrinkage does not impair its load-bearing capacity and transverse ribs of the gird provide its sufficient anchorage.

Keywords: foam concrete, CFRP grid, BFRP grid, slab foundation, reinforcement

Przestano do redakcji: 28.05.2017 r.

Przyjęto do druku: 01.09.2017 r. 